\title{
Antibiotic resistance pattern of bacteria isolated from various clinical specimens in a tertiary care hospital
}

\author{
Sailaja B. S. G. ${ }^{1}$, Prasad P.D. ${ }^{2}$ \\ ${ }^{1}$ Dr. B. S. G Sailaja, Assistant Professor, Department of Microbiology, GSL Medical College, Rajahmundry, Andhra \\ Pradesh, ${ }^{2}$ Dr. P.D. Prasad, District Hospital Pathologist, Chittoor, Andhra Pradesh, India. \\ Corresponding Author: Dr. P.D. Prasad, District Hospital Pathologist, Chittoor, Andhra Pradesh. E-mail: \\ bsgsailaja@gmail.com
}

\begin{abstract}
Background: Antibiotic resistance is a common phenomenon in bacteria, and it is a significant threat all over the world. With this a study was conducted to find the antibiotic resistance pattern of various bacterial isolates. Methods: This is a hospital-based study involving both in and outpatients. Patients with various infections were included, clinical specimen were collected accordingly. The pathogenic bacteria were isolated and identified. Antibiotic sensitivity testing was done by Kirby Bauer disc diffusion method. Results: The male female ratio was $1.23 ; 30 \%$ isolates were gram positive cocci and $70 \%$ were gram negative bacilli; Klebsiella spp $(30.5 \%)$ was the predominant isolate followed by Staphylococcus aureus (25\%); statistically the difference was not significant. Samples wise, predominant isolates were from urine followed by respiratory samples and skin samples; significant drug resistance was detected. Conclusion: A Significant rise of antibiotic resistance to various antibiotics in different classes of bacteria has been observed. Always there should be proper communication between the clinician and microbiologists is essential to get the best result while treating patient.
\end{abstract}

Keywords: Antibiotic resistance, Bacteria, Patients, Infections

\section{Introduction}

Antibiotic resistance of bacteria is significant threat all over the world. But the developing countries like India this is an even greater public health problem because India is one of the highest bacterial disease like urinary tract infections (UTI), respiratory tract infections (RTI), skin\& soft tissue infections (STI). With this, antibiotics have a significant role in mortality and morbidity $[1,2]$.

UTIs are important medical problem, usually caused by the microbial invasion of the urinary tract that extends from the renal cortex. The most common bacterial infection accounting for $35 \%$ of total hospital acquired infections (HAIs) [3,4].

RTI pose serious problems owing to their great prevalence with associated high mortality rates and economic status [5]. STI are common infections of the skin, subcutaneous tissue and muscle which may be minor, self-limiting may lead to life threatening diseases requiring; these may be complicated and uncomplicated infections [6].

Manuscript received: $8^{\text {th }}$ September 2019

Reviewed: $18^{\text {th }}$ September 2019

Author Corrected: $23^{\text {rd }}$ September 2019

Accepted for Publication: $28^{\text {th }}$ September 2019
India is one of the highest consumers of antibiotics in the world [7] and the drug resistance (DR) bacteria have increased in the last decade. Uncontrolled and inappropriate use of antibiotics is the main cause for DR. Among these, multi drug resistance (MDR), extremely drug resistance (XDR) TB, methicillin resistance Staphylococcus aureus (MRSA), penicillinase producing Neisseria gonorrhoea (PPNG), VA resistance Enterococci (VRE) are some important DR bacteria [8]. Surveillance studies are mandatory so that we every hospital can revise their antibiotic policies. With this a study was conducted to find the DR pattern of various bacterial isolates.

\section{Methods}

Study period: Study was conducted in the department of Microbiology, GSL Medical College from March to May 2019. Study protocol was approved by the institutional ethical committee.

Inclusion criteria: Individuals aged $\geq 18$ years, with various UTI, RTI, STIs attending inpatient and outpatients' departments were included in the study. 


\section{Original Research Article}

Exclusion criteria: Patients on antibiotic treatment for the last three months, known foreign bodies implants, mechanical heart valves were excluded from the study.

Study design: The patients were explained about the study protocol in detail and informed written consent was taken either from the participants or their representatives. Various clinical samples such as urine, sputum, BAL, pleural fluid, tracheal aspirate, bronchial wash, endotracheal tip, throat swabs, pus swabs, blood, IV catheter tips, body fluids (CSF, ascitic fluid, synovial fluid) were collected based on the site of infection. Specimen was transported to microbiology laboratory immediately. Direct microscopic examination such as gram stain, wet mount and culture sensitivity was done as per the standards $[9,10,11,12$, 13]. After overnight incubation, growth was classified by gram stain to gram positive cocci (GPC) and gramnegative bacilli (GNB). All the isolates were identified based on Gram staining and by using various biochemical reactions [13]. After identifying the bacteria, antibiotic sensitivity of isolates was done on Muller-Hinton agar (MHA) by the disk diffusion method [13], Escherichia coli ATCC 25922 was used as the control.

Statistical analysis: Statistical analysis was done by using SPSS version 21. Chi square test was to find statistical analysis, $\mathrm{P}<0.05$ was considered as statistically significant.

\section{Results}

During the study period the culture positivity was $302(100 \%) ; 30 \%$ were GPC and $70 \%$ GNB. The male female ratio was 1.23. Isolate wise, Klebsiella spp was the predominant among GNB and Staphylococcus aureus among GPC (Figure 1); statistically the difference was not significant.

Table-1: Number of isolates, clinical specimen wise; $\mathbf{n}(\%)$

\begin{tabular}{|c|c|c|c|}
\hline Specimen & GPC 92 (30) & GNB 210 (70) & Total 302 (100) \\
\hline Urine & $8(9.3)$ & $78(90.6)$ & $86(28.3)$ \\
\hline Respiratory & $47(46)$ & $55(53.9)$ & $102(33.6)$ \\
\hline Skin \& Soft tissue & $37(32.4)$ & $77(67.5)$ & $114(37.7)$ \\
\hline GPC: Gram positive cocci; GNB: Gram negative bacilli \\
\hline
\end{tabular}

Table-2: Antibiotic susceptibility pattern of the isolates in percentage.

\begin{tabular}{|c|c|c|c|c|c|c|c|c|c|c|c|c|c|c|c|}
\hline Isolate & $\begin{array}{l}\text { P \& } \\
\text { CON } \\
\text { GEN } \\
\text { ERS } \\
\text { P\&A } \\
\text { MP }\end{array}$ & $\begin{array}{l}2^{\text {nd }} \\
\text { Gen } \\
\text { CPS } \\
\text { CX }\end{array}$ & $\begin{array}{l}3^{\text {rd }} \\
\text { Gen } \\
\text { CPS } \\
\text { CTR } \\
\text { CTX } \\
\text { CAZ }\end{array}$ & $\begin{array}{l}\text { 4th } \\
\text { Gen } \\
\text { CPS } \\
\text { CP } \\
\text { M }\end{array}$ & $\begin{array}{l}\text { CIP } \\
\text { NX }\end{array}$ & $\begin{array}{l}\text { AK } \\
\text { GEN }\end{array}$ & $\begin{array}{l}\mathbf{E} \\
\mathbf{A Z}\end{array}$ & $\begin{array}{l}\text { VA } \\
\text { TEI }\end{array}$ & $\begin{array}{l}\mathbf{T E} \\
\mathbf{T}\end{array}$ & $\mathbf{L Z}$ & COT & NIT & PIT & AMC & $\begin{array}{l}\text { IMP } \\
\text { MRP }\end{array}$ \\
\hline \multirow[t]{2}{*}{ S.aureus } & S94 & S03 & S07 & S08 & S31 & S82 & S89 & S100 & S08 & S100 & S24 & S 89 & S100 & S100 & S100 \\
\hline & R06 & R97 & R93 & R92 & R69 & R18 & R11 & R0 & R92 & R0 & R76 & R11 & R0 & R0 & R0 \\
\hline \multirow[t]{2}{*}{ Sterpto } & S100 & S24 & S22 & $\mathrm{S} 12$ & & & S 54 & S100 & S89 & S100 & S55 & & S100 & S100 & S100 \\
\hline & R0 & R76 & R78 & R88 & & & R44 & R0 & R11 & R0 & R45 & & R0 & R0 & R0 \\
\hline \multirow[t]{2}{*}{ Entero } & S100 & S23 & S08 & S06 & S0 & S0 & S10 & S0 & & S0 & S0 & S 89 & S0 & S0 & S0 \\
\hline & R0 & R77 & R92 & R94 & R100 & R100 & R90 & R100 & & R100 & R100 & R11 & R100 & R100 & R100 \\
\hline \multirow[t]{2}{*}{ E.coli } & S97 & S25 & $\mathrm{S} 10$ & S08 & S31 & S14 & & & & & S24 & S 92 & S0 & S18 & S0 \\
\hline & R03 & R75 & R90 & R92 & R69 & R86 & & & & & R76 & R08 & R100 & R82 & R100 \\
\hline \multirow[t]{2}{*}{ Kleb } & S100 & S46 & S22 & S14 & S22 & S24 & & & & & S12 & S 81 & S04 & S22 & S0 \\
\hline & R0 & R54 & R78 & R86 & R78 & R76 & & & & & R78 & R19 & R96 & R78 & R100 \\
\hline \multirow[t]{2}{*}{ Pseudo } & S100 & S66 & S50 & S50 & S42 & S22 & & & & & S21 & S 77 & S04 & S28 & S0 \\
\hline & R0 & R36 & R50 & R50 & R58 & R78 & & & & & R79 & R23 & R96 & R72 & R100 \\
\hline \multirow[t]{2}{*}{ Proteus } & S100 & S24 & S08 & S08 & S22 & S22 & & & & & S11 & S 89 & S0 & S12 & S0 \\
\hline & R0 & R76 & R92 & R92 & R78 & R78 & & & & & R89 & R11 & R100 & R88 & R100 \\
\hline
\end{tabular}

S- Sensitive; R- Resistance; $\beta$ lactam group (Penicillin: P, Ampicillin: AMP); $2^{\text {nd }}$ generation Cephalosporins (Cefoxitin: CX); $3^{\text {rd }}$ generation Cephalosporins (Ceftriaxone: CTR, Cefotaxime: CTX, Ceftazidime: CAZ). $4^{\text {th }}$ generation Cephalosporins (Cefepime: CPM); Fluroquinolones (Ciprofloxacin: CIP, Norfloxacin: NX); Aminoglycosides (Amikacin: AK, Gentamycin: GEN); Macrolides (Erythromycin: E, Azithromycin; AZ); Glycopeptides (Vancomycin: VA, Teicoplanin: TEI); Tetracyclines: TET; Linezolid: LZ; Cotrimoxazole: COT; Nitrofurantoin: NIT; $\beta$ lactam $+\beta$ lactamase inhibitors (Piperacillin tazobactum: PIT, Amoxycillin clavulanic acid: AMC); Carbapenems (Meropenem: MRP, Imipenem: IMP). 
Original Research Article

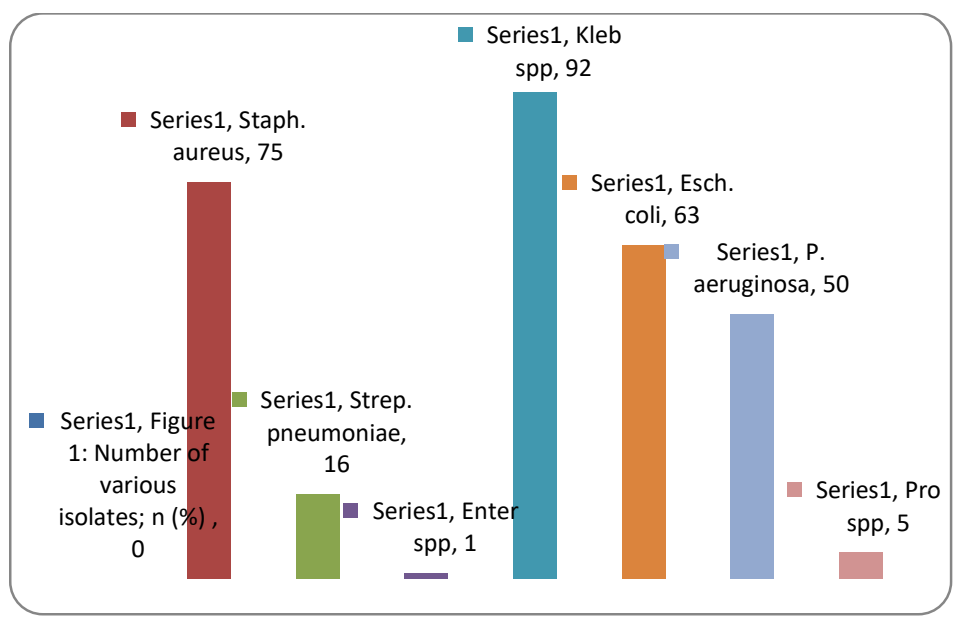

Figure-1: Prevalence of various isolates in the study (n)

Samples wise, predominant isolates were from urine followed by respiratory samples and skin samples (Table 1); significant DR was detected (Table 2).

\section{Discussion}

In this study, an attempt was made to find the prevalence of various bacteria as well as the drug susceptibility to various anti microbial agents. DR is the main concern for the treating specialists to choose the antibiotics especially for the hospitalized patients [14, 15] and also for pediatric group [16, 17]. For developing countries such as India, DR is a significant threat [18] because DR was reported to be one of the main causes of morbidity and mortality in India. This is mainly because of indiscriminate usage of antibiotics $[19,20]$.

Among GPC, Staph. aureus (75) is the prevalent pathogen isolated followed by streptococcus pneumoniae (16) and Enterococcus spp. (1); among GNB, the rate of isolation was Klebsiella species 92(30.4\%), Escherichia coli 63 (20.8\%), Pseudomonas aeruginosa 50 (16.5\%) and Proteus species 05 (1.6\%); DR was observed to almost all the pathogens.

Staph. aureus, commonest GPC showed 100\% sensitivity to LZ, V, IMP; $82 \%$ sensitivity to GEN. Azimi Taher et al., reported that highest resistance rate to $\mathrm{LZ}(\mathrm{R}=50 \%)$ and VA was reported to be an effective antibiotic [21]. Similar results were reported in the literature $[22,23,24]$. However, the results of these studies were not consistent with our findings and they had reported high resistance to VA.

In this study, most of the isolated were from UTIs; 86 were culture positive. Tsegaye Alemayehu et al., [25] also reported similar findings. The resistance rate of Klesiella in this study was, $100 \%, 86 \%, 78 \%$, respectively for IMP, CPM and CIP. Taher Azimi et al.,
[21] reported $12.8 \%, 18.5 \%$ and $21 \%$, DR respectively for levofloxacin, imipenem and ciprofloxacin.

As per the recent literatures, MDR organisms were reported from all over India for GP as well as GN bacteria [26]. This DR was reported not only towards old antibiotics, but recent anti bacterial agents such as carbapenem, tigecycline and $3^{\text {rd }}$ generation cephalosporins.

In this institution, there is a standard antibiotic policy and monthly there will be review meetings on this. And standard instructions to follow the results of antibiotic susceptibility testing. Inspite of these, DR was reported. Because of easy availability of antimicrobial agents in the market. From microbiological point also, proper quality control should be followed.

However, this study had certain limitation. Short duration, small sample size, no IP and OP categorization, no categorization of infections such as UTI, RTI and no species level identification.

\section{Conclusion}

A significant rise of antibiotic resistance to various antibiotics in different classes of bacteria has been observed. Always there should be proper communication between the clinician and microbiologists is essential to get the best result while treating patient.

\section{What the study adds to the existing knowledge?}




\section{Original Research Article}

The present study provides an epidemiological status of the significant rise of antibiotic resistance which is vital while designing the treatment plan.

\section{Author's contribution}

Dr. B. S. G Sailaja: Concept, study design and conduct of study.

Dr. P.D. Prasad P.D: Data analysis and manuscript preparation.

Findings: Nil; Conflict of Interest: None initiated Permission from IRB: Yes

\section{References}

1. Bhatia $\mathrm{R}$, Walia $\mathrm{K}$, Combating Antimicrobial Resistance in India: Technical challenges \& opportunities. Indian J Med Res. 2017;146(6):683-687. doi: 10.4103/ijmr.IJMR_19_17

2. Paul R, Ray J, Sinha S, Mondal J. Antibiotic resistance pattern of bacteria isolated from various clinical specimens: An Eastern Indian study Ind Comm Med and Pub Heal. 2017;4(4):1367-1371. doi: http://dx.doi.org/10.18203/2394-

6040.ijcmph20171377

3. Apurba Sankar Sastry, Sandhya Bhat K. Essentials of Medical Microbiology. Jaypee Medical Publishers. 2016.

4. Om PK, Raizada A. Approach to a patient with urosepsis. J Global Infect Dis. 2009;1(1):57-63.

5. Bulla A, Hitze KL. Acute Respiratory infections: A Review. Bull World Health Organ. 1978;56(3):481-498.

6. Matthew S.Dryden. Skin and soft tissue infection Microbiology and Epidemiology. Inter J Antimicrobial Agents. 2009;34(1):S2-S7. doi: 10.1016/S09248579(09)70541-2.

7. Common Clinical Diagnoses and conditions - skin \& soft tissue infections. J Hospital Med. 2010;5(2):37-38.

8. Laxminarayana R. Chaudhary RR. Antibiotic Resistance in India: Drivers \& Opportunities for action PLOS Med. 2016;13(3): e1001974. doi: https://doi.org/ 10.1371/journal. pmed.1001974.

9. Colle JG, Fraser AG, Marimon BP, Simmons A. Mackie \& Mc Cartney Practical Medical Microbiology. Elsevier. 2008.

10. Elmer W. Koneman, Stephen D. Allen, William M. Janda, Paul C. Schreckenberger, Washington C. Winn,
Jr Color atlas and textbook of diagnostic microbiology. Lippincott. 1997.

11. Monica Cheesbrough. District laboratory practice in tropical countries. Part 2 Cambridge University Press. 2002.

12. Clinical and Laboratory Standards Institute 2016. Performance Standards for Antimicrobial disc suspectibility tests: Approved Standard-12 $2^{\text {th }}$ edition, CLSI document M02-A12 Wayne. PA: Clinical laboratory Standards Institute.

13. Ehsan F. Hussein. Isolation, Identification and Antibiotic Susceptibility of pathogenic Bacteria Isolated from Clinical Samples. J Pharm Biol Sci. 2016;11(4):27-39.

14. Jorak A, Keihanian F, Saeidinia A, Heidarzadeh A, Saeidinia F. A cross sectional study on knowledge, attitude and practice of medical students toward antibiotic resistance and its prescription, Iran. Adv Environ Biol. 2014;8(17):675-681.

15. Folgori L, Bielicki J, Heath PT, Sharland M. Antimicrobial-resistant Gram-negative infections in neonates: burden of disease and challenges in treatment. Curr Opin Infect Dis. 2017;30(3):281-288. doi:10.1097 /QCO. 0000000000000371

16. Jafari M, Fallah F, Borhan RS. The first report of CMY, aac (6')-Ib and 16S Rrn Amethylase genes among Pseudomonas aeruginosa isolates from Iran. Arch Pediatr Infec Dis. 2013;1 (3):109-112. doi:10.5812/ pedinfect. 11392

17. Keihanian F, Saeidinia A, Abbasi K, Keihanian F. Epidemiology of antibiotic resistance of blood culture in educational hospitals in Rasht, North of Iran. Infect Drug Resist. 2018;11:1723-1728. doi:10.2147/ IDR. S169176

18. Miller LG, Perdreau-Remington F, Rieg G, Mehdi S, Perlroth J, Bayer AS. Necrotizing fasciitis caused by community-associated methicillin resistant Staphylococcus aureus in Los Angeles. N Engl J Med. 2005; 352 (14): 1445-1453. doi: 10.1056/ NEJMoa 042683

19. Combating Antimicrobial Resistance in India. New Delhi: WHO India; 2017.

20. WHO multi-country survey reveals widespread public misunderstanding about antibiotic resistance. Geneva: WHO Media centre; 2015. 


\section{Original Research Article}

21. Taher A, Saied M, Fatemeh F, Leila A, Zari G. Evaluating the antimicrobial resistance patterns among major bacterial pathogens isolated from clinical specimens taken from patients in Mofid Children's Hospital, Tehran, Iran: 2013-2018. Infect Drug Resist. 2019; 12: 2089-2102. doi: 10.2147/IDR.S215329.

22. Al-Naqshbandi AA, Chawsheen MA, Abdulqader HH. Prevalence and antimicrobial susceptibility of bacterial pathogens isolated from urine specimens received in rizgary hospital - Erbil. J Infect Public Health. 2018;12(3): 330-336. doi: 10.1016/j.jiph. 2018.11.005. Epub 2018 Dec 3.

23. Ullah O, Khan A, Ambreen A, Ahmad I, Akhtar T, Gandapor AJ. Antibiotic Sensitivity pattern of bacterial isolates of neonatal septicemia in Peshawar, Pakistan. Arch Iran Med. 2016;19(12): 866-869. doi: 0161912/AIM.009.
24. Hui-min Y, Yan-ping W, Lin Liu Y, Shamsi BH, Bo $\mathrm{H}$, Xu-chun $\mathrm{M}$. Analysis of distribution and antibiotic resistance of pathogens isolate from the paediatric population in Shenmu Hospital from 20112015. J Int Med Res. 2018;46(1):225-233. doi:10.1177/0300060517716343

25. Alemayehul T, Ali M, Mitiku E, Hailemariam M. The burden of antimicrobial resistance at tertiary care hospital, southern Ethiopia: a three years' retrospective study. BMC Infect Disease. 2019;19:585-592. doi: https://doi.org/10.1186/s12879-019-4210-1

26. Mendem SK, Gangadhara TA, Shivannavar CT, Gaddad SM. Antibiotic resistance patterns of Staphylococcus aureus: A multi center study from India. Microbial Pathogen. 2016; 98:167-170. doi: 10.1016/j. micpath. 2016.07.010. Epub 2016 Jul 20.

\section{How to cite this article?}

Sailaja B. S. G., Prasad P.D. Antibiotic resistance pattern of bacteria isolated from various clinical specimens in a tertiary care hospital. Trop J Path Micro 2019;5(9):714-718.doi:10.17511/jopm.2019.i09.16. 